\title{
Helping Businesses to Identify Their Opportunities
}

\author{
Hakan Butuner
}

\begin{abstract}
The purpose of this paper is to help businesses to define their business opportunities that are most attractive and feasible for them. It is intended to find the factors that would affect and change the outlook mostly in the current status and anticipated future, based on the results obtained from environmental analysis. In short, using the trends to be revealed by the environmental analysis, it is possible to anticipate how the field of business in which we operate or plan to enter will evolve in the future. Accordingly, based on the various potential scenarios and their potential impacts on the industry, and by matching them with the competitive advantages of the business, the potential opportunities for the business are identified. Another intention here is to provide strategic planners an easily understandable and applicable new approach for clarifying their businesses' opportunities, by assembling the disconnected and disorderly ideas, processes and techniques. Throughout this paper, for the sake of understanding this new approach well enough, an example case is introduced.
\end{abstract}

Index Terms-business opportunities; opportunities; scenarios; strategy.

\section{INTRODUCTION}

By using the trends to be revealed by the environmental analysis, it is possible to anticipate how the field of business in which we operate or plan to enter will evolve in the future. It is important that this is continuously repeated taking into consideration evolving conditions and innovations. Thus, assumptions are grouped under various scenarios, their potential impacts on the industry are identified, and the potential status in the industry is defined. Scenarios:

- Internally consistent views of the future.

- Focus on discontinuity and change.

- Explore the impact of the change on key players and how they respond to the environment.

The opportunities that may be offered and posed for the business under the positive scenarios to come out from scenario analysis must be identified. Moreover, determining the strengths of the company compared to its competitors will be able to carry the analysis to a satisfactory result, as in [4]. In short, competitive advantages of the business need to be matched with the potential positive (attractive) scenarios in the industry to come up with the potential opportunities for the business in the industry are identified. Table 1 shows matrices of opportunities.

The competitive advantages when matched with the result of scenarios provide the critical foundation for opportunities formulation.
TABLE I: MATRIX OF OPPORTUNITIES

\begin{tabular}{cccc} 
& & \multicolumn{2}{l}{ Possibility of Success } \\
& & High & Low \\
\multirow{2}{*}{ Appeal } & High & 1 & 2 \\
& Low & 3 & 4
\end{tabular}

No 1: The opportunities in this field are the most appealing ones for the business.

No 2 and 3: The opportunities in this field should be followed for the changes that could develop the possibilities of appeal or success.

No 4: The opportunities in this field are at insignificant level for the business.

Opportunities, by definition, arise in cases where the unresolved problems and unsatisfied expectations and needs are identified for the use of products in the market, and if solutions can be produced for these.

An opportunity, then, is the possibility to do things both differently and better than how they are being done at the moment, as in [7]. In economic terms, differently might take the form of offering a new product or of organizing the business in a different way. Better means the product offers utility in terms of an ability to satisfy human needs, that existing products do not.

Throughout this paper, for the sake of understanding well, an example case, as in [2], will also be introduced to support the suggested approach:

"Abler by Robomedika will create an innovative brand and establish a company which designs and produces innovative medical machinery. The company will touch patient's life and make life easier for handicapped people. The brand is Abler that will be the innovative and new generation wheel chair and will be designed by Robomedika engineers."

\section{Matching Positive Scenarios With Competitive POSITIONS}

By testing out total market attractiveness of each positive scenario, you would be able to screen out investment opportunities even before considering what kind of competitive advantages you might be able to attain. The attractiveness is the net benefits less the costs (not just the benefits.)

Drivers of growth are used for assessing the market attractiveness of a particular positive scenario in Fig. 1. This is accomplished through vector analysis (where arrows represent strength of growth drivers.)

Vector analysis, as in [1], is a way of mapping the impact of forces for growth in an industry. The length of the vector arrow represents the perceived strength of the force driving growth.

Growth brakes are the forces which throw growth into 
reverse. To identify the potential growth brakes you need to amplify the weak signals concept from the environment. The upwards arrows are growth drivers, the downwards arrows are brakes on growth. A very long downward arrow represents a stopper on growth.

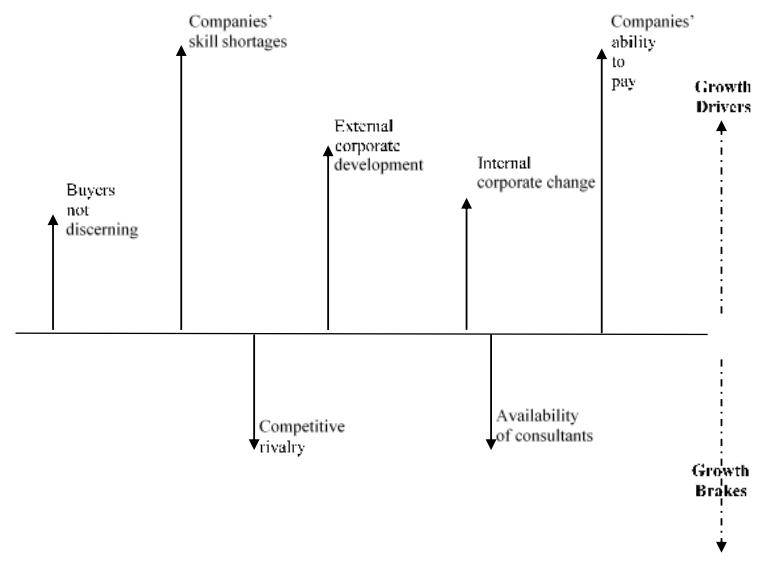

Fig. 1. Market attractiveness of a particular scenario - Example

Besides market attractiveness of a scenario, to position a business effectively on the GE grid, as in [6], you also need to take some view of its competitive position, as in [5], with regard to the particular scenario. The following ten key criteria will usually suffice:

- Brand, image and reputation

- Simplicity of product/market focus, or alternatively a relevant and broad offering

- Relative market (or niche) share

- Product and service performance

- Distribution channels

- Cost base

- Responsiveness (but this doesn't mean reactiveness)

- Technical and non-technical competencies

- Financial strength

- Management skills

The above factors can be scored as strong, average or weak. Also, the relative importance of the factors can be assessed by weighting some factors as being more important than others.

"Accordingly, it is assumed that by analyzing the internal factors of Abler and comparing its strengths with main competitors, product performances, cost base, responsiveness, technical and non-technical competencies and management skills can help Abler taking a competitive position w.r.t the so-called positive scenario (Table 2)."

\section{BUSINESS OPPORTUNITIES}

Fig. 2 shows the GE, as in [6], grid that enables you to

- Position a business, having determined market attractiveness of a scenario and competitive position of a business with regard to the particular scenario

- Evaluate business opportunities

- Reposition a business (from right to left on the GE grid, or even (by shifting the business' market focus) diagonally north-west)

- Challenge the adequacy of investment to achieve such a repositioning (both long-term investment and revenue costs with longer term benefits)

- Compare your positioning with other key competitors operating in the same or different market segments

TABLE II: COMPETITIVE POSITION W.R.T. A PARTICULAR SCENARIO EXAMPLE

\begin{tabular}{|l|c|c|c|}
\hline & Weak & Medium & Strong \\
\hline Brand, Image and Reputation & + & & \\
\hline $\begin{array}{l}\text { Simplicity of Product/Market } \\
\text { Focus }\end{array}$ & & + & \\
\hline $\begin{array}{l}\text { Relative Market (or Niche) } \\
\text { Share }\end{array}$ & + & & \\
\hline $\begin{array}{l}\text { Product and Service } \\
\text { Performances }\end{array}$ & & & + \\
\hline Distribution Channels & + & & + \\
\hline Cost Base & & & + \\
\hline Responsiveness & & & + \\
\hline $\begin{array}{l}\text { Technical and Nontechnical } \\
\text { Competencies }\end{array}$ & & & + \\
\hline Financial Strength & + & & \\
\hline Management Skills & & & \\
\hline
\end{tabular}

Starting at the north-west point, business units with high total market attractiveness and strong competitive position are called Big Bang to suggest that they are likely to throw off a lot of cash. Businesses with medium total market attractiveness and strong position are still likely to generate considerable cash (and earnings). While moving south, a strong position in a low market attractiveness area is more likely to struggle to produce a good profits and cash stream.

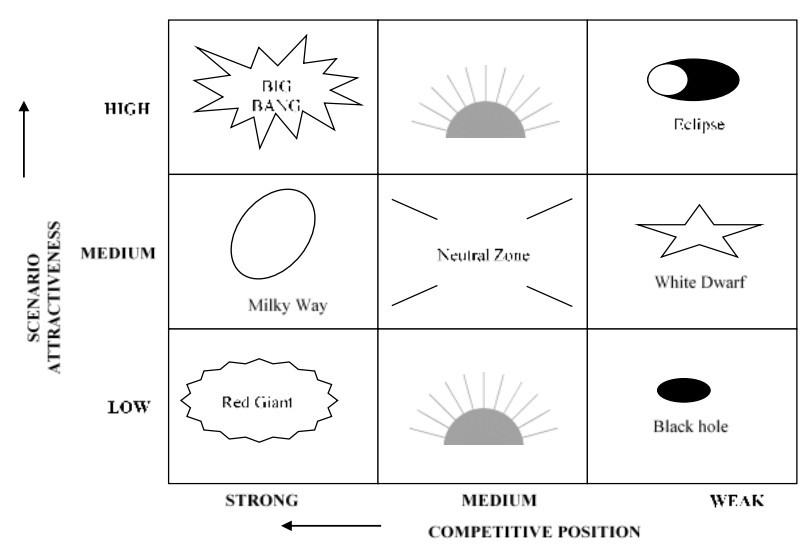

Fig. 2. Business opportunities

Moving to the middle of the GE grid, an average position in a highly attractive market may again be very well rewarded. But this Sunrise position may easily slip in terms of competition position, becoming an Eclipse or move into the middle, Neutral Zone.

At the bottom of the grid, a Sunset business (average competitive position in a market with low attractiveness) will probably struggle to make adequate profit and be hard pushed to generate much cash. Equally, a weak position in a medium attractive market is also unlikely to generate reasonable financial returns (the White Dwarf - this is so named because it is a burnt-out star).

A special danger is where a business thinks that it will be able to enter the market in the Big Bang or Sunrise cell of 
the GE matrix, but actually enters in the Black Hole position. Because of lags in recognizing this problem it may be some time before it is reflected in financial results and its root causes are diagnosed, therefore leading to increased, rather than reduced, commitment to this opportunity move.

"Accordingly, the particular positive scenario can be considered as a Big Bang for Abler as market attractiveness of this scenario is quite high and as Abler has high competitive position w.r.t this scenario, Abler can turn this into an opportunity for itself.

High profitability and low number of players point out the attractiveness of the medical market, but high $R \& D$ expenses and wide distribution channels require a great amount of investment capital. Accordingly, the market is quite attractive for financially powered players but quite risky for startups.

However, on one side there are high-tech global giants and on the other side there are low cost Chinese companies, which means it is not easy to compete with any one of these sides and therefore entry barrier should be considered seriously."

\section{SCREENING AND SELECTING OpPoRtunities}

Not all opportunities are equally valuable. A business with limited resources cannot pursue every opportunity with which it is faced. It must select those opportunities that are going to be the most rewarding. The key decisions in screening and selecting opportunities relate to the size of the opportunity, the investment necessary to exploit it, the rewards that will be gained, and the risks likely to be encountered. Specifically, the decision on selecting opportunities, illustrated in Fig. 3, should be based on the answers to the following questions, as in [3]:

- Market attractiveness: Is the market (or segment) inherently attractive (consider key growth drivers and brakes?)

- Competitive advantage: Are we likely to have (and able to sustain) a competitive position?

- Financial attractiveness: Are we likely to make enough money out of it?

- Implementation capability: Do we have the capability, resources, and commitment to implement it effectively?

For answering the above questions, you may use quantitative and qualitative approaches.

- Qualitative approach:

○ Who are the customers?

$\circ$ How are they differentiated from noncustomers?

- What needs do these customers have in relation to the product category?

- How well do consumers find that current offerings satisfy those needs?

$\circ$ In what ways are current offerings unsatisfactory?

- What are the customers' attitudes towards the product category in general?

- Why do non-customers not use the product category?

○ How might they be attracted to it?

- If the product is not valuable, how might other types of product be used as a substitute?

- How does this define a gap for an innovative offering?

$\circ$ How they are normally informed about the product category?

○ Who influences the consumer when they use the product?

- How do they greet innovations in the product category? (Positively or with suspicion?)

- Quantitative approach:

○ How large is the market (its volume)?

- How much is worth (its value)?

$\circ \quad$ How fast is it growing?

- How large are the key segments in the market?

- How many customers are there?

- How much and how often do they buy?

- What are the market shares of the competitors supplying the market?

o What level of investment do competitors make in developing the market and defending them?

\begin{tabular}{|c|c|c|c|c|}
\hline & \multicolumn{4}{|c|}{ Financial Attractiveness } \\
\hline $\begin{array}{c}\text { Implementation } \\
\text { Capability }\end{array}$ & $\begin{array}{l}\text { Very } \\
\text { High }\end{array}$ & High & Moderate & Low \\
\hline $\begin{array}{c}\text { A- } \\
\text { Absolutely } \\
\text { Capable }\end{array}$ & & & & \\
\hline $\begin{array}{c}\text { E- } \\
\text { Especially } \\
\text { Capable }\end{array}$ & & Opp & & \\
\hline I-Capable & & & & \\
\hline $\begin{array}{l}\text { O-Very } \\
\text { Little }\end{array}$ & & & & \\
\hline U-Uncertain & & & & \\
\hline $\begin{array}{c}\text { X-Not } \\
\text { Applicable }\end{array}$ & & & & \\
\hline
\end{tabular}

The diameter of circle represents the relative position of an opportunity w.r.t. the market attractiveness and competitive position of it (which is gathered from GE Grid).

Fig. 3. Selection of opportunities - prioritization

\section{CONClusion}

Using the trends to be revealed by the environmental analysis, it is possible to anticipate how the field of business in which we operate or plan to enter will evolve in the future. Accordingly, potential impacts of the various scenarios on the industry are identified. Additionally, by taking into consideration the characteristics of the business that offer competitive advantages, the potential opportunities for the business in the industry are identified.

In conclusion, this paper is introduced to help a business to define its business opportunities by matching positive 
scenarios with the competitive position of the business. Thus, the intention here is to provide strategic planners an easily understandable and applicable new approach for clarifying their businesses' opportunities, by assembling the disconnected and disorderly ideas, processes and techniques.

\section{REFERENCES}

[1] H.I. Ansoff, Corporate Strategy, London: Penguin, 1970.

[2] H. Butuner, Case Studies in Strategic Planning, Boca Raton: CRC Press, 2016.

[3] H. Butuner, Systematic Strategic Planning: A Comprehensive Framework for Implementation, Control and Evaluation, Boca Raton: CRC Press, 2015.

[4] M.A. Hitt, R.D. Ireland, and, R.E. Hoskisson, Strategic Management: Competitiveness and Globalization, Mason: Thomson South-Western, 2005.

[5] C.A. Montgomery, and M.E. Porter, Strategy for Seeking and Securing Competitive Advantages, Watertown: Harward Business School Press, 1991.

[6] E.M. Rasiel, The McKinsey Way, Columbus: McGraw-Hill Trade, 1999. [7] P.A. Wickham, Strategic Entrepreneurship, London: Pearson Education Limited, 2004.

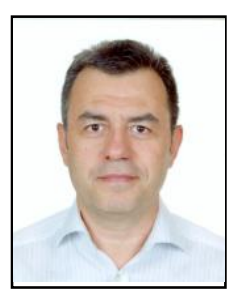

H. Butuner received his B.Sc. in industrial engineering from Middle East Technical University, Ankara; MBA from Bilkent University, Ankara; and Ph.D. in engineering management from the University of Missouri-Rolla, USA.

He has been active both in academic and professional fields for several years as a Project Manager in overseas; as a Strategic Planning and Business Development Director; and as an Operations Improvement Program Manager. During the same periods, he has been lecturing in the Business Schools and/or Industrial Engineering Departments of well-known Universities.

Currently, he is acting as the Affiliates of several US companies in Industrial Management and Engineering consulting and training fields in Turkey. Additionally, he is the President of Institute of Industrial Engineers - Turkish Professional Chapter; and Board Member of Institute of High Performance Planners in Kansas City.

During his career path, Dr. Butuner has participated in several projects. Plus, he has several publications and books (especially in Operations Management and Improvement, and Strategic Planning). 